\title{
O POSICIONAMENTO DE MARCA SOB UM OLHAR DA ENGENHARIA DE PRODUÇÃO
}

DOI: 10.37702/2175-957X.COBENGE.2021.3715

Lissandra Gouvêa Freitas - lissandragfreitas14@gmail.com

Universidade do Estado de Minas Gerais

Rua Alonso Cordeiro 363

35650-000 - Pitangui - MG

Sarah Alcântara Rocha Borges - sarahrocha_@hotmail.com

Universidade do Estado de Minas Gerais

Rua São Paulo 148

35500-006 - Divinópolis - MG

Tiago Santos Veloso - tiagoengen@hotmail.com

Universidade do estado de Minas Gerais

Rua candeias 1300

35501-248 - Divinópolis - MG

Vânia dos Santos Ventura - vania.ventura@uemg.br

Universidade do estado de Minas Gerais

Rua Curvelo 160

33501-072 - Divinópolis - MG

Resumo: A proposta deste trabalho é abranger de forma conceitual, as influências nos processos organizacionais pelo posicionamento de marca do negócio através da literatura disponível e a junção de impactos na cadeia produtiva. Todos os fatores abordados abaixo são de extrema importância na Engenharia de Produção, ao mesmo tempo em que se define como um diferencial competitivo para a organização. Este vínculo é o objeto de estudo que será tratado com o objetivo de garantir clareza na importância da relação entre o posicionamento de uma marca com o fluxo produtivo de uma empresa, assim como os processos que o permeiam.

Palavras-chave: Marca, posicionamento, engenharia de produção. 


\section{O POSICIONAMENTO DE MARCA SOB UM OLHAR DA ENGENHARIA DE PRODUÇÃO}

\section{INTRODUÇÃO}

O espaço que uma determinada marca ocupa no mercado, já há um certo tempo, deixou de ser definido apenas pela qualidade de seu produto ou serviço. O cliente é visto cada vez mais como um parceiro do negócio e passa a atuar diretamente nas decisões da empresa ao definir quais posicionamentos ele exigirá daquela organização.

Segundo Serralvo e Furrier (2004) o valor de uma marca e o posicionamento que ela terá, vem de sua habilidade em ter um significado exclusivo, claro e positivo na mente do cliente. Sendo consequências diretas da estratégia de segmentação de mercado e diferenciação de produto.

As estratégias escolhidas além de determinar o desempenho da marca apresenta uma relação direta com a Engenharia de Produção na medida que impacta no desempenho competitivo do negócio como um todo.

O posicionamento definido de uma marca influência no investimento que ela receberá no desenvolvimento do seu produto. Ou seja, impacta na qualidade buscada dos insumos, no planejamento e controle da produção, nos quesitos logistícos de entrega e de comunicação da marca, nos resultados e perfis dos profissionais que já trabalham na empresa, bem como os a serem contratados.

DiMingo (1988) afirma que há dois lados do posicionamento. O primeiro, é ligado ao negócio, em que identifica e seleciona um mercado ou um segmento, tendo como alvos os concorrentes e definindo estratégias de desempenho competitivo, ou seja, saber o que o mercado quer e necessita, identificar pontos fortes e fracos dos concorrentes e avaliar as habilidades para atender as exigências de maneira mais eficiente. O segundo é voltado para o a percepção do consumidor e envolve a criação da identidade, seja ela corporativa e/ou do produto, utilizando a comunicação para atingir e influenciar a decisão de compra do consumidor.

Ao tratar as variáveis intrínsecas a construção e longevidade de uma organização, como variáveis ambientais, demográficas, econômicas, psicológicas, culturais, entre outras, será visto, no decorrer do estudo, a importância do posicionamento escolhido da marca para impulsionar e validar ações externas e investimentos internos de uma empresa.

\subsection{Objetivo geral}

O objetivo do presente estudo é verificar e descrever os fatores vinculados ao posicionamento da marca a partir das condições e variáveis envolvidas na Engenharia de Produção. Desta forma, busca apresentar a relação entre a estrutura de abordagem escolhida para o negócio-marca e o impacto no desempenho competitivo, nos funcionários da organização, no planejamento e controle da produção, a fim de estabelecer uma relação entre brand, empreendimento e mercado.

\subsection{Justificativa}

Por consequência do aumento pela busca por profissionais com uma visão sistêmica, é vista a necessidade das organizações em visualizar e compreender o seu todo por meio das partes que o forma para auxílio na tomada de decisão. Com essa visão é possível enxergar não apenas a interligação dos processos, mas também as influências que exercem uns nos outros. 
Simultâneamente, a busca por uma econômia voltada apenas para produção eficiente de bens encontra-se basicamente inexistente, evidenciando a ascensão da economia dos serviços que agrega valor aos seus produtos com o posicionamento que adotam.

Dessa forma, o presente trabalho se justifica ao analisar a lacuna existente nos estudos acadêmicos de Engenharia de Produção em sua relação com o posicionamento de marca, a fim de constatar os impactos de um sobre o outro para garantir maior acertividade nos processos organizacionais, desde a concepção da ideia do produto até a percepção transmitida ao cliente no ponto de venda.

\subsection{Referencial teórico}

Um termo de fácil interpretação, o "posicionamento", como a própria palavra sugere, refere-se ao determinado local, lugar, ponto que uma empresa, marca ou produto ocupam. Sua real origem não é acordada, porém foi na década de 70 que começou a ser difundido após Al Reis e Jack Trout escreverem diversos artigos intitulados "A Era do Posicionamento", que foram publicados pela revista Advertising Age, conforme evidenciado por Mourad e Serralvo (2018).

A definição do conceito também tem várias interpretações, sendo que para Serralvo e Furrier (2004) a percepção do posicionamento está associado a configuração de modelos e variáveis que se organizam afim de construírem uma identificação própria. Essa percepção dos elementos pode, então, serem compreendidos de forma estratégica ou para um processo de falta de diferenciação ou padronização de referências.

Como exposto por Mourad e Serralvo (2018), o posicionamento, para muitos autores, é defendido como sendo a posição que a organização ocupa na mente de seu público-alvo, ou seja, a reação à uma ação contida em seu produto. Assim, a percepção gerada ao consumidor sobre a empresa como um todo, torna-se extremamente valiosa para os gestores inspecionarem e garantirem um posicionamento eficaz e eficiente, como aponta Nogueira e Sette (2013).

O termo "posicionamento" e sua ampla interpretação, como evidencia Telles e Queiroz (2013), assumiu um novo patamar de importância sendo percebido como um componente essencial para a manutenção da competitividade da organização.

Ao mesmo tempo, a qualidade a qual os produtos e serviços devem ser entregues envolvem alta conformidade as especificações, aparência atrativa, número baixo de defeitos, entre outros. As tecnologias também devem ser adequadas e os processos bem definidos, garantindo uma gestão da qualidade que possibilite o aumento da produtividade, bem como sua competitividade. (MARINO, 2006)

A qualidade total torna-se, então, essencial. De acordo com Campos (2014) para que ela aconteça é necessário que haja o controle da qualidade de maneira que se elimine a causa fundamental dos problemas, ou seja, de qualquer resultado no processo ou sistema que não seja desejado. Sendo que esses problemas podem ser de qualidade, custo, atendimento, moral ou segurança.

Os pontos a serem considerados pela qualidade total que irão influenciar diretamente em seu posicionamento são apresentados na Figura 1.

Figura 1 - Elementos da qualidade total 


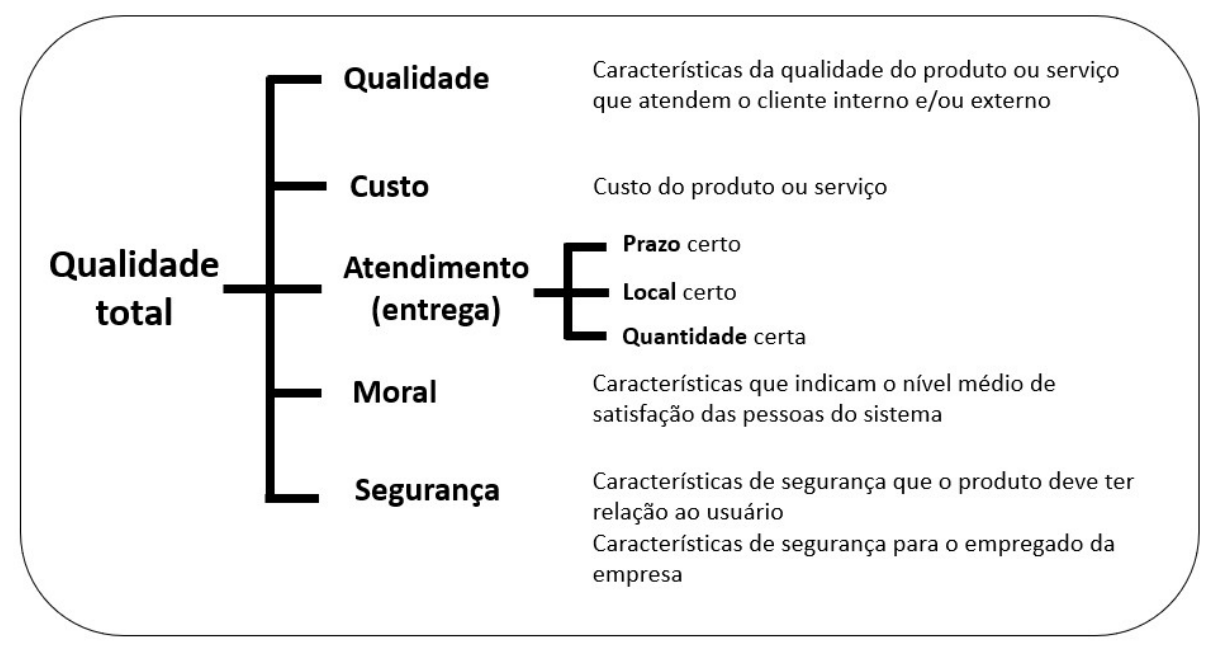

Fonte: Reprodução de Campos (2014)

Abordando um dos pontos mencionado na tabela, temos a qualidade dos produtos e serviços prestados no ambiente interno e externo. O significado de qualidade a ser considerado é o evidenciado por Bernardo (2009) que aponta a qualidade como sendo o que atende de forma correta, confiável, acessível, com segurança e no momento certo a necessidade do cliente.

A qualidade dos processos internos sendo, então, cumprida há uma tendência do desempenho do negócio e da prestação de serviços, bem como de seus produtos, terem uma igual qualidade percebida por seu cliente externo, por, segundo Oliveira (2011) existir uma correlação positiva entre ambos.

Assim sendo, a combinação da qualidade total, a melhoria contínua, a atenção aos processos e à seu público-alvo é de crucial importância para garantir seu posicionamento, como aponta Eisner (2011). Ele exemplifica com o caso da Disneyland Paris, originalmente chamada de Euro Disney.

Eisner (2011) continua a descrever que o resort de entretenimento teve seu nome alterado após a Disney - com sua cultura organizacional pautada em sempre que há algo que pode ser melhorado, isso é melhorado - ter percebido que, para os europeus, a palavra "euro" remeter instantaneamente a moeda e, consequentemente, ao comércio, o que gerava a quebra em toda a "magia" espalhada pela empresa.

Dessa forma, como aponta Gonzalez e Martins (2011), a melhoria continua é definida como um processo de inovação constante, de forma focada e contínua, que com seus passos pequenos, alta frequência em pequenos ciclos e vistos separadamente, podem aparentar impactos pequenos, mas combinados contribuem significativamente para 0 desempenho da empresa.

Eisner (2011) acrescenta como todos os processos na Disney combinam ações de recursos humanos, chamados de elenco, e físicos, os cenários, de várias maneiras para produzir diferentes resultados, sem perder o fator crucial que é a magia de encantar seus clientes, os seus convidados.

Esses processos bem definidos ressaltam outra caracteristica notária da Disney: o bom atendimento. Como mostrado na tabela 1: Elementos da qualidade total, esse é outro aspecto de extrema importância para as organizações e Demonte (2013) o aponta como um dos fatores para a sobrevivência e sucesso de um negócio. Uma vez que, um atendimento ruim pode levar um potencial cliente a desistir da compra de um produto, e até gerar uma imagem ruim do empreendimento. 
Demonte (2013) também relata o outro lado: um bom atendimento pode gerar uma compra por uma pessoa que não estava interessada em adquirir o produto, ao mesmo tempo que contribue para a fidelização do cliente.

Todos esses pontos configuram-se como um diferencial competitivo que impactam em toda a cadeia produtiva. Segundo Kelm, Sausen e Kelm (2015), há dois fatores que irão originar o diferencial competitivo, sendo eles as condições iniciais, que representam a posição da empresa, no decorrer do tempo, em relação ao ambiente externo, e as escolhas dos dirigentes, ou seja, as opções estratégicas dos gestores.

Baseado nesses aspectos, Aaker (1996, p.221), aponta que uma identidade e uma posição de marca bem concebidas e implementadas trazem uma série de vantagens à organização: orientam e aperfeiçoam a estratégia de marca; proporcionam opções de expansão da marca; melhoram a memorização da marca; dão significado e concentração para a organização; geram uma vantagem competitiva; ocupam uma posição sólida contra a concorrência; dão propriedade sobre um símbolo de comunicação; provêm eficiências em termos de custos de execução.

Blankson (2001) defende que o estudo sobre posicionamento de marcas globais é importante não só para o meio acadêmico, como também para o meio empresarial. Tornase necessário, portanto, não só comunicar o avanço dos estudos na área, bem como identificar lacunas de pesquisa sobre o posicionamento de marcas globais.

Para Kotler (2000), o posicionamento, pode assumir diferentes configurações de acordo com a estratégia que se deseja atingir, o que provoca mudanças na marca, no preço, embalagem do produto, etc.

O quadro abaixo descreve as estratégias de posicionamento.

Quadro 1 - - Estratégias de posicionamento de marcas ou serviços.

\begin{tabular}{|c|c|c|}
\hline Estratégias & Descrição \\
\hline $\begin{array}{c}\text { Posicionamento por } \\
\text { atributo }\end{array}$ & $\begin{array}{c}\text { Quando o posicionamento é baseado na performance de características ou } \\
\text { propriedades específicas da marca ou do serviço, tais como padrão de qualidade, } \\
\text { competência do pessoal, criatividade, grau de flexibilidade ou condição de entrega. }\end{array}$ \\
\hline $\begin{array}{c}\text { Posicionamento por } \\
\text { benefício }\end{array}$ & $\begin{array}{c}\text { Quando a marca ou serviço é posicionado como líder em relação a um certo } \\
\text { benefício ou resultado para os clientes, ou seja, resolução de problemas, economia } \\
\text { de tempo, redução de custo, conveniência ou melhoria de resultados. }\end{array}$ \\
\hline $\begin{array}{c}\text { Posicionamento por } \\
\text { aplicação }\end{array}$ & $\begin{array}{c}\text { Quando o posicionamento apresenta o serviço como sendo o melhor para uma dada } \\
\text { ocasião de uso ou aplicação, como para "períodos de demanda baixa", "ambientes } \\
\text { com espaço limitado" ou "situações de vendas decrescentes". }\end{array}$ \\
\hline $\begin{array}{c}\text { Posicionamento por } \\
\text { usuário }\end{array}$ & $\begin{array}{c}\text { Quando o serviço ou marca é posicionado para uma determinada categoria de } \\
\text { usuário, como para "professores universitários", "organizações de serviços" ou } \\
\text { "indústrias de confecção de vestuário". }\end{array}$ \\
\hline $\begin{array}{c}\text { Posicionamento por } \\
\text { concorrente }\end{array}$ & $\begin{array}{c}\text { Quando a marca ou serviço é comparado ou posicionado como melhor em relação à } \\
\text { concorrência, como "organização mais comprometida com os clientes" ou "agência } \\
\text { de comunicação mais premiada". }\end{array}$ \\
\hline $\begin{array}{c}\text { Posicionamento por } \\
\text { classe de serviços }\end{array}$ & $\begin{array}{c}\text { Quando o serviço é posicionado como líder em uma determinada classe de serviços, } \\
\text { como "parque temático de recreação" ou "serviços de comunicação integrada de } \\
\text { marketing". }\end{array}$ \\
\hline $\begin{array}{c}\text { Posicionamento por } \\
\text { qualidade e preço }\end{array}$ & $\begin{array}{c}\text { Quando o posicionamento comunica que a marca ou serviço oferece aos } \\
\text { consumidores potenciais a melhor relação preço-qualidade ou o melhor valor. }\end{array}$ \\
\hline
\end{tabular}

Fonte: Elaborado a partir de KOTLER, 2000; AAKER, 1996.

Assim, relacionamos que o branding é entendido como a postura empresarial, ou a filosofia adotada pela gestão, em colocar a marca como centro nas tomadas de decisões. Sendo que, a marca é entendida, nesse momento, justamente como o sentimento que os 
consumidores têm pela marca, que é determinada por seu posicionamento, como aponta Hiller (2004).

Segundo Steenkamp (2017), observando os gastos que as organizações, de variados setores, dispendem com publicidades de suas marcas, fica evidente como o branding é importante para a economia. O Quadro 2 relaciona as 10 empresas que mais destinaram gastos a publicidade durante o ano de 2014.

Quadro 2 - Investimentos com publicidade por empresa e segmento industrial no ano de 2014

\begin{tabular}{|c|c|c|}
\hline Empresa & Setor & $\begin{array}{c}\text { Investimento em Publicidade } \\
\text { (Milhões) }\end{array}$ \\
\hline Procter \& Gamble & Bens de consumo embalados & $\$ 10.125$ \\
\hline Unilever & Bens de consumo embalados & $\$ 7.394$ \\
\hline L'Oréal & Cuidado pessoal & $\$ 5.264$ \\
\hline Coca-Cola & Bebidas & $\$ 3.279$ \\
\hline Toyota Motor Cor & Automotiva & $\$ 3.185$ \\
\hline Volkswagen & Automotiva & $\$ 3.171$ \\
\hline Nestlé & Alimentícia & $\$ 2.930$ \\
\hline General Motors & Automotiva & $\$ 2.849$ \\
\hline Mars Inc & $\begin{array}{c}\text { Comidas para animais de } \\
\text { estimação }\end{array}$ & $\$ 2.569$ \\
\hline McDonald's & Restaurantes & $\$ 2.494$ \\
\hline
\end{tabular}

Fonte: Steenkamp (2017)

De acordo com Da Silva (2001), a estratégia se constitui em cinco conceitos: a de ser um plano que indica uma direção para o futuro; um padrão; uma posição que determinados produtos em determinados mercados ocupam; a maneira fundamental de uma organização fazer as coisas; e, ainda, uma manobra específica para enganar um concorrente.

Com esses pontos definidos, a competitividade entra novamente em questão, sendo ressaltado por Da Silva (2001), que a vantagem competitiva é a capacidade de uma organização em formular e implementar as estratégias estabelecidas, que lhe permitam ampliar e conversar de forma sustentável e duradoura no mercado, a partir de seu posicionamento.

Da Silva (2001) continua apontando os fatores que constituem a competitividade, sendo eles: sistêmicos (não controláveis pela organização), estruturais (que podem ou não ser controlados pela organização) e internos (controláveis pela organização).

Dessa forma, ressalta Sampaio (2002), que a única área onde ainda é possível obterse vantagem competitiva sustentável por um período de tempo considerado longo é através da construção e manutenção de marcas fortes.

Troiano (2003) afirma que, quando as empresas avançam no brand equity, ela desenvolve a capacidade de criar negócios como um todo. Nesse contexto são esperados três efeitos no crescimento do poder da marca, que acabam por ter maior ou menor sinergia em relação a gestão da marca. A primeira delas é a maior propensão ao aumento de market-share, devido ao poder de atração que a marca exerce sobre seus clientes; a segunda é a maior facilidade do desenvolvimento de novos negócios com a mesma marca, ou seja, o poder dessa marca possibilita sua extensão; já a terceira, refere-se a possibilidade de atuar no mercado com maiores margens (praticando preços premium), aumentando sua lucratividade.

Conforme a análise de Troiano (2003), a Figura 2 a seguir, demonstra os efeitos do brand equity: 
Figura 2 - Análise dos efeitos do brand equity.

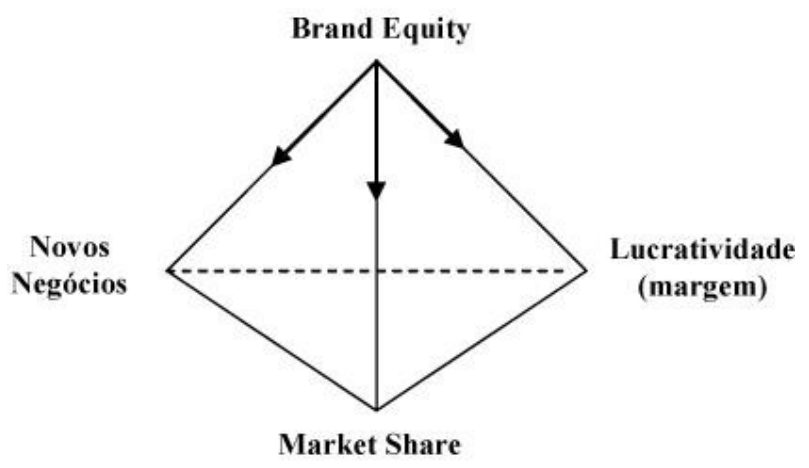

Fonte: Troiano (2003)

Nesse mesmo foco, Aaker (1998) defende ainda que o brand equity tem o potencial de agregar valor a empresa, por afetar a confiança do consumidor na decisão de compra, devido sua experiência anterior ou familiaridade com a marca e, assim, proporcionando o motivo para compra e satisfação. Também proporciona maiores margens, por permitir a cobrança de preços premium, bem como a menor utilização de promoções e descontos. Dessa forma, constitui uma plataforma para o crescimento através da extensão de marca. Além de, impulsionar o canal de distribuição e proporcionar vantagem competitiva, o que, geralmente, acaba sendo uma barreira de entrada para concorrentes.

Encrementando esses pensamentos, Nunes e Haigh (2003) afirmam que a marca cria valor econômico para as empresas por causar impacto nas curvas de oferta e demanda. Em relação a demanda, a marca capacita o produto a alcançar um preço maior, a aumentar o volume de vendas e a reter e aumentar seu uso (market-share) pela lealdade dos clientes.

\section{METODOLOGIA}

O método de pesquisa utilizado no presente trabalho foi pesquisa exploratória com o objetivo de comprovar a relação entre o posicionamento de marca e a Engenharia de Produção, associada à pesquisa bibliográfica com a seleção de autores, livros e trabalhos que abordassem o panorama buscado. Além disso, aplicou-se uma abordagem qualitativa para se compreender e interpretar temas de conceitos amplos e com diversas aplicações determinadas conforme a decisões estratégicas das organizações.

Com isso, como maneira de expor as análises de conceitos e ideias, o trabalho caracteriza-se como uma pesquisa qualitativa pautada na revisão bibliográfica, por buscar obter resultados e respostas acerca da problematização apresentada. É fundamentada em citações e ideias que apresentam importância na definição e construção da análise da relação apontada. Para tal, o trabalho é moldado a partir do método conceitual-analítico, uma vez que conceitos e ideias de outros autores, que correspondem com a temática abordada, são utilizados para a construção de uma análise científica sobre o objeto de estudo.

\subsection{RESULTADOS E DISCUSSÕES}

A ascensão da economia dos serviços, que agrega valor aos produtos com o posicionamento que adotam, evidência a lacuna existente nos estudos acadêmicos de Engenharia de Produção sobre o assunto. Dessa forma, o presente estudo busca evidenciar essa relação e seus impactos, na medida em que se visualiza e compreende a interligação dos processos e influências que exercem uns sobre os outros. 
A partir da pesquisa exploratória foi possível encontrar as definições de posicionamento de marca, que destaca a premissa da percepção do consumidor pela marca. Essa percepção faz com que a organização passe a ocupar um determinado espaço na mente do seu público e, consequentemente, se torna componente importante para a manutenção de sua competitividade.

Com isso, uma das primeiras relações percebidas foi a com a busca pela qualidade total. Os clientes de uma determinada marca ou seviço esperam que o produto solicitado seja entregue dentro de suas especificações, aparência atrativa e número baixo ou nenhum de defeitos. Ou seja, o consumidor o adquire com a expectativa do que lhe foi oferecido e esteja de acordo com os padrões conhecidos daquela marca.

É nesse momento que a qualidade total é inserida, focalizando a necessidade do controle dos processos, de adquirir insumos de qualidade e de ressaltar os problemas que possam ser eliminidados. Os principais pontos a serem considerados são: qualidade, custo, atendimento, moral e segurança. Ou seja, a qualidade deve atender de forma correta, confiável, acessível, com segurança e no momento certo a necessidade do cliente. Assim, compreende-se como a garantia da qualidade é considerada uma expressão de grande impacto nas relações comerciais.

Oliari e De Souza Zambon (2014) evidenciam esse ponto através da Apple. A marca se tornou forte devido a qualidade oferecida em seus produtos e em seu relacionamento com o cliente. A Apple projeta tudo pensando em trazer uma experienciação única para o seu consumidor e, assim, um impacto positivo para a empresa. Isso faz com que ela fidelize seus clientes entregando-lhes produtos que falam por si só, através das experiências e com produtos de fácil uso e alta qualidade.

Juntamente com a qualidade total, é interessante que a empresa esteja sempre atenta a inovação e a melhoria contínua. Focalizando a última, Mesquita e Alliprandini (2003) apontam a indispensabilidade em enxergar a melhoria como um processo, sendo este o que diferenciará uma empresa da outra.

Mesquita e Alliprandini (2003) continuam definindo três tipos de melhoria: o controle de processos, a melhoria reativa e a melhoria proativa, estabelecendo uma prática sistemática preestabelecida para melhoria e solução de problemas, bem como para capacitação e uso de ferramentas apropriadas.

Isso é, uma organização tendo seus processos bem definidos, busca pela qualidade total, com a identificação e correção de falhas de forma rápida e eficiente, e melhoria contínua, seu propósito fica mais evidenciado, e então, seu posicionamento ocupa um local mais claro e relevante para seu cliente.

Todos esses fatores convergem em um ponto: a estratégia da organização. De Oliveira (2004) significa a estratégia como a habilidade de um empresa em formular e implementar táticas concorrenciais que permitam ampliar ou conservar, de forma duradoura, sua posição e participação no mercado de maneira sustentável.

Essa estratégia deve ser construída desde o ínicio da organização, em seu Planejamento Estratégico, por ser o que moldará seu posicionamento de marca e definirá seus três principais pilares, sua missão, visão e valores. Esses pilares, de acordo com Comin (2012), devem ser entendidos como: a razão da existência da empresa, onde ela pretende chegar, e seus padrões éticos, repectivamente.

A Amazon, quarta empresa mais valiosa do mundo em 2020 segundo a Forbes, exemplifica a importância de uma estratégica bem definida. Em seu site, aponta sua missão como "ser a empresa mais centrada no cliente da Terra", ressaltando que é a mesma desde que seu website foi lançado em 1995. Seu objetivo é claro e simples e molda toda a organização de maneira que seus processos são desenvolvidos a partir dele em um alto padrão de qualidade. 
Focalizando no cliente, ela apresenta uma grande seleção de produtos "de A a Z", com uma estrutura de custos e preços mais baixos, agilidade para compra e em suas entregas e com uma experiência satisfatória para o consumidor. Esse processo ciclíco e bem estruturado em sua estratégia possibilita a tomada de "decisões inteligentes e rápidas, agir com precisão, inovar e inventar, e manter o foco na satisfação dos clientes".

Diferente da Amazon, a Puma teve que repensar suas estratégias e, principalmente, sua posição. Inserida em um mercado agressivo e perdida em seu próprio posicionamento, a Puma não possuía relevância em nenhum dos segmentos a que estava inserida e, não apenas isso, não era a primiera opção de compra, como aponta Monteiro (2010).

Agregando ao mencionado, Monteiro (2010) evidencia que o resultado foi uma crise financeira, a partir do ano de 1985. Após oito anos consecutivos de prejuízos a empresa começou um plano de reestruturação de longo prazo. Em uma de suas etapas apresentava a necessidade de reposicionar a marca. A Puma construiu, então, uma estratégia em que aliava-se não só ao esporte mas como também à moda e ao estilo de vida, por isso, investiu em seus diferenciais: o design de seus produtos e inovação nos materiais utilizados.

Após se reestabelecer no mercado, começou a investir cada vez mais em seu posicionamento, patrocinando nomes fortes no esporte como Usain Bolt e, mais recentemente, Neymar Júnior. Assim, como notado na tabela 3 - Investimentos com publicidade por empresa e segmento industrial no ano de 2014, cada vez mais as grandes marcas tem investido em publicidade. Isso porque ela vem deixado de ser apenas um elemento de marketing da empresa e vêm sido entendida como uma estratégia que a influênciará em todos os seus processos.

Com todos esses pontos esfatizados, sua estratégia definida e aonde predente chegar (visão), a organização consegue preparar para enfatizar seus pontos fortes e corrigir e/ou apontar melhorias para seus pontos fracos. E é nesse momento que ela definirá qual estratégia de posicionamento adotará, conforme descrito na tabela 2 - Estratégias de posicionamento de marcas ou serviços, e que impactará toda a cadeia produtiva, com a empresa entendendo seus pontenciais a serem destacados e suas limitações a serem melhoradas.

O passo seguinte, como apresenta Brito e Brito (2012), é a possibilidade de criar valor sobre seu produto e sua marca, a partir dos processos e estrátegias bem definidas e poscionamento adotado, e estabelecer uma vantagem competitiva frente a seus competidores, bem como uma relação entre o que o cliente está disposição a pagar e o custo de oportunidade da empresa.

Acrescentado a vantagem competitiva, a criação de valor entre empresas está relacionado também ao brand equity. Por estar alinhado ao espaço que um marca apresenta na mente do consumidor e em sua confiança na decisão de compra, após os pontos mencionados no decorrer deste trabalho, o brand equity é seu último passo afim de proporcionar maiores margens e constituir uma plataforma para o crescimento através da extensão de marca.

Portanto, uma posição de marca bem concebida e implementada traz uma série de vantagens à organização que impactam todos os seus processos. O posicionamento orienta e aperfeiçoa estratégias e opções de expansão da marca e da organização, dá significado e concentração para a empresa, gera vantagem competitiva, ocupa posição sólida contra a concorrência e provêm eficiências em termos de custos de execução.

Assim, percebe-se que a escolha da estratégia de posicionamento para o negóciomarca impacta seu desempenho competitivo, o planejamento e controle da produção com a qualidade total e melhoria contínua, estabelecendo uma relação clara entre brand, empreendimento e mercado. 
Os pontos apresentados, definem o posicionamento da marca e seus efeitos nos processos. Os mais perceptíveis, como mencionando, consistem na demanda, no preço e na qualidade pretendida. Todos esses fatores são de extrema importância na Engenharia de Produção, ao mesmo tempo em que define-se como um diferencial competitivo para a organização.

\section{Considerações FINAIS}

O posicionamento da marca, reflete a essência da empresa. Oliveira (2007) explica que um dos fatores que definem bem uma marca é a impressão de todos os seus consumidores sobre as pessoas que a consomem, assim como sua experiência pessoal de vivência com ela.

Buscou-se retratar neste trabalho os processos internos que compõem essa impressão, sendo assim, a marca é construída por tudo que está ligado a construção de uma empresa, principalmente as pessoas.

Concluiu-se que uma marca é composta por conceitos e ações que vão muito além do que é comunicado ao público. Para garantir a qualidade total e/ou uma estratégia de brand equity, quando comunicada no posicionamento de determinada marca, é necessário que os processos internos se adequem a tal conceito, neste momento vê-se o forte vínculo da engenharia de produção com a marca e seu posicionamento no mercado.

A garantia de um diferencial competitivo passa por esse vínculo descrito acima, o qual permite inovações, ganho de produtividade, controle de processos, entre outras melhorias que o engenheiro de produção é preparado para atuar.

\section{REFERÊNCIAS}

AAKER, David A. Criando e administrando marcas de sucesso. São Paulo: Futura, 1996.

AAKER, D. A. Marcas - Brand Equity - Gerenciando o valor da marca. São Paulo: Negócio, 1998.

AMAZON. Sobre a Amazon. Disponível em: https://www.amazon.jobs/pt/landing_pages/aboutamazon\#: :text=A\%20miss\%C3\%A30\%20da\%20Amazon\%20\%C3\%A9,centrada\%20no \%20cliente\%20da\%20Terra\%E2\%80\%9D.\&text=Com\%20tecnologias\%20inovadoras\%20 de\%20primeira,clientes\%20em\%20todo\%20o\%20mundo.. Acesso em: 2 fev. 2021.

BERNARDO, Alynne Pontes. Percepção da qualidade de serviços sob a otica do cliente interno: estudo de caso da DCC/SUPLAN. UFPB-CSSA-DCI, 2009.

BLANKSON, Charles. Some issues about the concept of positioning: an overview. Atlantic Marketing Association Conference, 2001.

BRITO, Renata Peregrino de; BRITO, Luiz Artur Ledur. Vantagem competitiva e sua relação com o desempenho: uma abordagem baseada em valor. Revista de Administração Contemporânea, v. 16, n. 3, p. 360-380, 2012.

CAMPOS, Vicente Falconi. Qualidade total-Padronização de empresas. Falconi Editora, 2014 
COMIN, Fabio Scorsolini. Missão, visão e valores como marcas do discurso nas organizações de trabalho. Psico, v. 43, n. 3, p. 6, 2012.

DA SILVA, Christian Luiz. Competitividade e estratégia empresarial: um estudo de caso da indústria automobilística brasileira na década de 1990. Revista da FAE, v. 4, n. 1, 2001.

DE CASTRO MARINO, Lúcia Helena Fazzane. Gestão da qualidade e gestão do conhecimento: fatoreschave para produtividade e competitividade empresarial. XIII SIMPEP, 2006.

DE OLIVEIRA, Letícia. A estratégia organizacional na competitividade: um estudo teórico. Revista eletrônica de administração, v. 10, n. 4, 2004.

DEMONTE, Maria Luiza Bergo. Atendimento ao cliente como diferencial competitivo: Disney. 2013.

DIMINGO, Edward. The fine art of positioning. The journal of business strategy, v. 9, n. 2, p. 34, 1988.

EISNER, Michel. O jeito Disney de encantar os clientes. Saraiva, São Paulo, 2011.

GONZALEZ, Rodrigo Valio Dominguez; MARTINS, Manoel Fernando. Melhoria contínua e aprendizagem organizacional: múltiplos casos em empresas do setor automobilístico. Gestão \& Produção, v. 18, n. 3, p. 473-486, 2011.

HILLER, Marcos. Branding: a arte de construir marcas. Editora Trevisan, 2014.

KELM, Maiquel Silva; SAUSEN, Jorge Oneide; KELM, Martinho Luis. Posicionamento Estratégico na Cadeia Produtiva do Leite: Análise das Estratégias Competitivas de uma Cooperativa de Produtores de Leite. Organizações Rurais \& Agroindustriais, v. 17, n. 3, 2015.

KOTLER, P. Administração de Marketing: a Edição do Novo Milenio. Tradução: Bazan Tecnologia e Linguistica. São Paulo: Prentice Hall, 2000.

LOPES, Gabriela Lima; FADEL, Roberta Regina. Branding e a estratégia de construção de marca: o caso da rede de cafeterias Starbucks. 2006.

MESQUITA, Melissa; ALLIPRANDINI, Dário Henrique. Competências essenciais para melhoria contínua da produção: estudo de caso em empresas da indústria de autopeças. Gestão \& Produção, v. 10, n. 1, p. 17-33, 2003.

MONTEIRO, Renata de Andrade. Estudo de caso da marca Puma: um reposicionamento de marca de sucesso. 2010.

NOGUEIRA, CAROLINE MENDONÇA; SETTE, R. de S. Posicionamento em Marketing: Produção acadêmica Brasileira sob a ótica da Meta-Análise. IV Encontro de Ensino e Pesquisa em Administração e Contabilidade, 2013. 
NUNES, G.; HAIGH, D. Marca: valor do intangível - Medindo e gerenciando seu valor econômico. São Paulo: Atlas, 2003.

OLIARI, Deivi Eduardo; DE SOUZA ZAMBON, Cláudia Neli. APPLE: Como esta marca se tornou sinônimo de qualidade e hoje é a marca mais valiosa do mundo. Anais Intercom Sul, 2014.

OLIVEIRA, Tânia Vanessa dos Santos Jordão Simões. O Marketing Interno e a qualidade do serviço prestado pelo back-office ao front-office como factor determinante da satisfação do cliente externo. 2011. Tese de Doutorado.

SAMPAIO, R. Marcas de A a Z: como construir e manter marcas de sucesso. Um guia para fazer da sua marca a principal força do seu negócio. Rio de Janeiro: Campus, 2002.

SERRALVO, Francisco Antonio; FURRIER, Márcio Tadeu. Fundamentos do posicionamento de marcas: uma revisão teórica. Anais do VII Seminários em Administração, 2004.

STEENKAMP, J.-B. Global Brand Strategy. London: Palgrave Mac - millan UK, 2017. TELLES, Renato; QUEIROZ, Maciel Manoel. POSICIONAMENTO DE MARCA: UMA PERSPECTIVA DA EVOLUÇÃO DO CONCEITO. Revista Científica Hermes, n. 8, p. 187207, 2013.

TROIANO, J. Além da retórica: medindo a força da marca. Revista da ESPM. v. 10, n. 2, p.6-18, 2003.

\section{THE BRAND POSITIONING FROM A PRODUCTION ENGINEERING POINT OF VIEW}

Abstract: The purpose of this work is to cover, in a conceptual way, the influences in the organizational processes by the business brand positioning through the available literature and the combination of impacts in the production chain. All the factors discussed below are extremely important in Production Engineering, while it is defined as a competitive differential for the organization. This link is the object of study that will be addressed to ensure clarity on the importance of the relationship between the brand positioning and the production flow of a company, as well as the processes that permeate it.

Keywords: Brand, positioning, production engineering. 